\title{
PEMANFAATAN TEKNOLOGI INFORMASI BAGI INDUSTRI KONFEKSI DI KECAMATAN GIANYAR
}

\author{
Ni Ketut Dewi Ari Jayanti, dan Gde Sastrawangsa \\ STMIK STIKOM Bali \\ E-mail: daj@stikom-bali.ac.id ; sastrawangsa@stikom-bali.ac.id
}

\begin{abstract}
ABSTRAK. Industri konfeksi merupakan salah satu sektor industri kecil yang terletak di Kecamatan Gianyar, Kabupaten Gianyar. Industri konfeksi di Kecamatan Gianyar merupakan industri konfeksi yang mengolah bahan baku menjadi barang jadi. Usaha utama dari industri ini adalah pakaian. Salah satu usaha industri konfeksi di Kecamatan Gianyar yang dimiliki oleh Bapak YA. Saat ini produk konfeksi yang dihasilkan adalah baju kaos polos atau sablon, kemeja, kaos polo, seragam sekolah, baju partai, jaket dan lain-lain. Permasalahan yang dihadapi oleh mitra adalah pengelolaan pencatatan keuangan yang dilakukan saat ini oleh mitra masih dikelola secara manual dan mitra tidak memiliki identitas konfeksi yang dapat dijadikan sebagai identitas pada produk garmen yang dihasilkan. Adapun solusi yang diberikan pengusul yaitu dengan melakukan kegiatan dalam pengabdian ini yaitu (1) memberikan pengetahuan kepada mitra melalui pelatihan dalam pengelolaan keuangan yaitu pencatatan pembelian bahan baku, pencatatan pengeluaran, serta pencatatan penjualan produk konfeksi dengan menggunakan aplikasi spreadsheet dari Microsoft, yaitu Microsoft Excel, (2) membuat desain label woven. Kegiatan pengabdian telah dilaksanakan yang diawali dengan sosialisasi kegiatan dan dilanjutkan dengan pelatihan pengelolaan keuangan dengan Microsoft Excel. Selain itu selama berjalannya kegiatan pengabdian ini, pengusul juga telah membuatkan desain logo dan desain label woven bagi mitra. Kegiatan pengabdian berjalan dengan lancar dan mitra puas dengan pelatihan dan desain yang dibuat.
\end{abstract}

Kata kunci: Garmen; Teknologi Informasi; Pengelolaan UKM

ABSTRACT. The confectionary industry is one of the small industrial sectors located in Gianyar District, Gianyar Regency. The confectionary industry in Gianyar Subdistrict is a confectionary industry that processes raw materials into finished goods. The main business of this industry is clothing. One of the confectionary industry businesses in Gianyar Subdistrict is confectionary industry which is owned by Mr. YA. At present, the clothing products produced are plain t-shirts or screen printing, shirts, polo shirts, school uniforms, party clothes, jackets and others. The problem faced by partners is the management of financial records that are carried out now by partners are still managed manually and partners do not have a confection identity that can be used as an identity on the garment product produced. The solution given by the proposers is by conducting activities in this service, namely (1) providing knowledge to partners through training in financial management, namely recording raw material purchases, recording expenses, and recording sales of confection products using a spreadsheet application from Microsoft, namely Microsoft Excel, (2) making confectionary industry woven label designs. Service activities have been carried out which began with the dissemination of activities and continued with financial management training with Microsoft Excel. In addition during this service activity, the proposer has also made the confectionary industry woven logo design and woven label design. The service activities went smoothly and the partners were satisfied with the training and design made.

Keywords: Garment; Information Technology; SME's Management

\section{PENDAHULUAN}

Kata "busana" diambil dari bahasa Sansekerta "bhusana". Namun dalam bahasa Indonesia terjadi penggeseran arti "busana" menjadi "padanan pakaian". Meskipun demikian pengertian busana dan pakaian merupakan dua hal yang berbeda. Busana merupakan segala sesuatu yang kita pakai mulai dari ujung rambut sampai ke ujung kaki (Ernawati, 2008). Industri yang memproduksi busana secara masal dikenal dengan nama industri konfeksi.

Industri konfeksi merupakan salah satu sektor industri kecil yang terletak di Kecamatan Gianyar, Kabupaten Gianyar. Industri konfeksi di Kecamatan Gianyar merupakan industri konfeksi yang mengolah bahan baku menjadi barang jadi. Adapun usaha utama dari industri ini adalah pakaian.

Salah satu usaha industri konfeksi di Kecamatan Gianyar adalah yang dimiliki oleh Bapak YA. Saat ini produk konfeksi yang dihasilkan adalah baju kaos polos atau sablon, kemeja, kaos polo, seragam sekolah, baju partai, jaket dan lain-lain. Usaha konfeksi Bapak YA baru berjalan selama 2 tahun dengan memperkerjakan 3 orang tenaga dari desa setempat.

Produksi yang dilakukan oleh Bapak YA berdasar pada pemesanan yang dilakukan oleh pelanggan. Selama menjalankan usaha konfeksi, Bapak YA melakukan pencatatan keuangan secara manual. Dimulai dari pencatatan pembelian bahan baku, pencatatan pengeluaran serta pencatatan penjualan produk. Akibatnya sering terjadi kesalahan perhitungan yang mengakibatkan informasi keuangan yang tidak seimbang. Penelusuran riwayat data keuangan juga sangat sulit dilakukan dengan cara manual. Selain itu, produk konfeksi dikemas hanya menggunakan plastik biasa, dan pada produk tidak terdapat label woven yang dapat dijadikan sebagai identitas konfeksi.

Berdasarkan analisis tersebut, pengusul mencoba untuk melakukan kegiatan dalam pengabdian ini yaitu (1) memberikan pengetahuan kepada mitra melalui pelatihan dalam pengelolaan keuangan yaitu pencatatan pembelian bahan baku, pencatatan pengeluaran, serta pencatatan penjualan produk konfeksi dengan menggunakan aplikasi spreadsheet dari Microsoft, yaitu Microsoft Excel, (2) 
membuat desain logo dan label woven. Logo usaha bagi mitra Bapak YA sangat penting, karena dijadikan sebagai identitas bagi usahanya. Identitas usaha dapat diaplikasikan pada produk dan media pemasaran seperti brosur, label serta kartu nama. Logo menurut Febriansyah(Febriansyah, 2014) menjadi sebuah pengakuan, kebanggan, inspirasi kepercayaan, kehormatan, kesuksesan, loyalitas dan keunggulan yang tersirat ke dalam suatu bentuk atau gambar. Logo juga merupakan bagian yang penting untuk menunjukkan keberadaan suatu pembeda produk dengan produk lainnya. Logo diyakini dapat memberikan efek pengakuan tertentu kepada setiap orang yang melihat atau memakai. Kegiatan pelatihan pengelolaan keuangan sangat penting dilakukan agar mitra usaha konfeksi Bapak YA memiliki pengetahuan mengenai pembiayaan usaha sehingga dapat mengelola usahanya dengan baik. Pengelolaan keuangan (Setia, 2015), merupakan usaha memaksimalkan profit/keuntungan, dan meminimalkan biaya untuk mendapatkan pengambilan keputusan yang maksimum dalam menjalankan usahanya ke arah perkembangan dan usaha yang berjalan.

Dari analisis yang dilakukan pada usaha konfeksi milik Bapak YA, maka dapat dirumuskan beberapa permasalahan sebagai berikut :

1. Kegiatan pengelolaan pencatatan keuangan yang dilakukan saat ini oleh mitra masih dikelola secara manual, semua pembelian bahan baku, pencatatan pengeluaran, serta pencatatan penjualan produk konfeksi dilakukan pada buku-buku kas.

2. Sering terjadi ketidak seimbangan dalam catatan keuangan, sehingga mitra tidak tahu berapa penghasilan tepatnya setiap bulan.

3. Penelusuran riwayat data keuangan mitra yang sulit dilakukan secara manual.

4. Tidak memiliki identitas konfeksi yang dapat dijadikan identitas produk.

Berdasarkan permasalahan yang terjadi pada usaha konfeksi Bapak YA, maka dapat diuraikan suatu solusi. Adapun solusi yang dapat diberikan adalah

1. Memberikan pengetahuan kepada mitra mengenai pengelolaan keuangan atau yaitu pencatatan pembelian bahan baku, pencatatan pengeluaran, serta pencatatan penjualan produk konfeksi. Proses memberikan pengetahuan ini melalui pelatihan kepada Bapak YA tentang pengelolaan keuangan menggunakan Ms. Excel untuk pencatatan pembelian bahan baku, pencatatan pengeluaran, serta pencatatan penjualan produk konfeksi. Manfaat yang dapat diperoleh melalui pelatihan pengelolaan keuangan adalah Bapak YA dapat memiliki data keuangan yang lebih baik, serta mengetahui pendapatan pastinya setiap bulan.

2. Membuat desain logo dan label woven, agar usaha konfeksi Bapak YA memiliki identitas produk.

\section{METODE}

Kegiatan pengabdian ini dilaksanakan pada mitra usaha konfeksi, yaitu mitra Bapak YA yang berasal dari Banjar Lebih Duur Kaja Kabupaten Gianyar. Kegiatan ini dimulai pada tahun 2018 hingga 2019.

Pengumpulan data dalam kegiatan pengabdian ini dilakukan untuk memperoleh gambaran tentang keadaan usaha konfeksi mitra. Adapun keadaan usaha mitra konfeksi adalah, dari sisi ekonomi mendata jumlah produksi, harga produk, biaya produksi serta pendapatan. Sedangkan dari sisi sosial mendata pendidikan mitra Bapak YA, serta pengetahuan mitra tentang pengelolaan usaha dan pengelolaan keuangan. Teknik pengumpulan data dilakukan dengan wawancara langsung ke mitra usaha konfeksi Bapak YA, yaitu dengan mengajukan beberapa pertanyaan langsung ke mitra. Berdasarkan data yang diperoleh didapatkan masalah yang dihadapi mitra.

Kegiatan ini berlangsung selama tiga (3) bulan. Kegiatan diawali dengan sosialisasi kegiatan, pelatihan pengelolaan keuangan dengan Microsoft Excel, pembuatan desain logo dan label woven dan evaluasi kegiatan pengabdian. Untuk lebih jelas, jadwal kegiatan dapat dilihat pada Tabel 1

\section{Tabel 1. Jadwal Kegiatan Pengabdian}

\begin{tabular}{|c|c|c|c|c|}
\hline \multirow[t]{2}{*}{ No } & \multirow[t]{2}{*}{ Kegiatan } & \multicolumn{3}{|c|}{$\begin{array}{l}\text { Waktu Kegiatan } \\
\text { (bulan) }\end{array}$} \\
\hline & & 1 & 2 & 3 \\
\hline 1 & Sosialisasi Kegiatan Pengabdian & & & \\
\hline 2 & $\begin{array}{l}\text { Pelatihan pengelolaan keuangan } \\
\text { dengan Ms. Excel }\end{array}$ & & & \\
\hline 3 & $\begin{array}{l}\text { Pembuatan desain logo dan label } \\
\text { woven }\end{array}$ & & & \\
\hline 4 & Evaluasi Kegiatan Pengabdian & & & \\
\hline
\end{tabular}

Kegiatan diawali dengan sosialisasi ke mitra terkait kegiatan pengabdian yang akan dilakukan. Pada tahap sosialisasi pelaksana kegiatan menyampaikan rangkaian kegiatan yang dilakukan yaitu pelatihan yang dilanjutkan dengan praktek/ workshop kepada mitra mengenai pengelolaan keuangan menggunakan aplikasi Microsoft Excel, penyampaian desain logo dan label woven. Mengenai desain logo dan label woven mitra memberikan masukan terkait desain tersebut. Pada akhir kegiatan dilakukan evaluasi kegiatan pengabdian masyarakat. Gambaran pelaksanaan kegiatan dapat dilihat pada Gambar 1

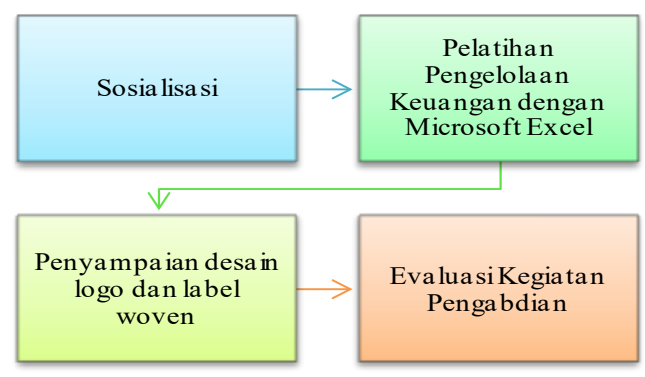

Gambar 1. Pelaksanaan Kegiatan 


\section{HASIL DAN PEMBAHASAN}

Kegiatan diawali dengan sosialisasi ke mitra terkait kegiatan pengabdian yang akan dilakukan. Pada tahap sosialisasi pelaksana menyampaikan rangkaian kegiatan yang akan dilakukan.

Pada kegiatan pelatihan mitra diberikan pengetahuan mengenai pengenalan Microsoft Excel. Pada pengenalan Microsoft Excel mitra diberikan penjelasan umum apa itu Microsoft Excel serta penjelasan mengenai lembar kerja pada Microsoft Excel.

Pelaksana dalam memberikan pengenalan Microsoft Excel langsung memberikan contoh dengan menunjukkan langsung menu-menu yang ada pada lembar kerja. Materi dapat dilihat pada Gambar 2.

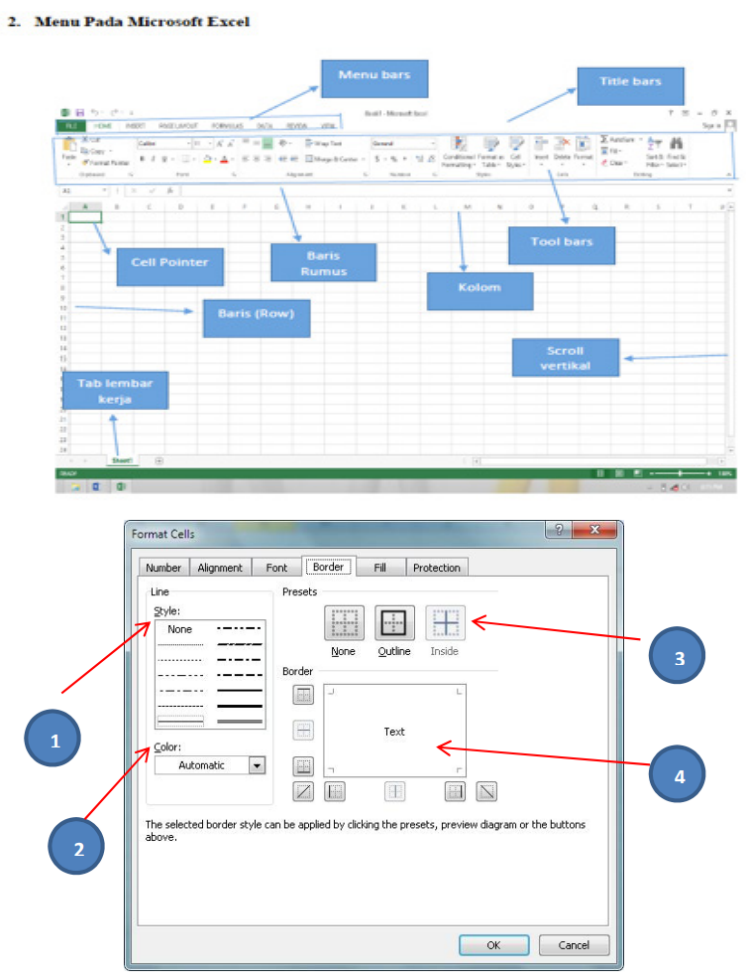

Gambar 2. Menu dan Pengaturan Border Pada Microsoft Excel

Setelah mitra paham mengenai Ms. Excel, mitra diberikan pengetahuan mengenai langkah sederhana pengelolaan keuangan dan bagaimana mengelolanya menggunakan Ms. Excel. Selanjutnya mitra dilatih langsung melalui kegiatan workshop untuk melakukan kegiatan pengelolaan keuangan dengan Ms. Excel. Diawal mitra dilatih untuk memasukkan data kedalam lembar kerja. Selanjutnya mitra diberikan pengetahuan dan langsung mempraktekkan membuat rumus sederhana pengelolaan keuangan. Ilustrasi hasil workshop seperti pada Gambar 3

Agar produk konfeksi lebih dikenal masyarakat, diperlukan identitas produk berupa logo dan label woven. Pembuatan logo dan label woven dengan memanfaatkan teknologi informasi yaitu menggunakan aplikasi Adobe Photoshop. Desain logo dan label woven dapat dilihat seperti pada Gambar 4

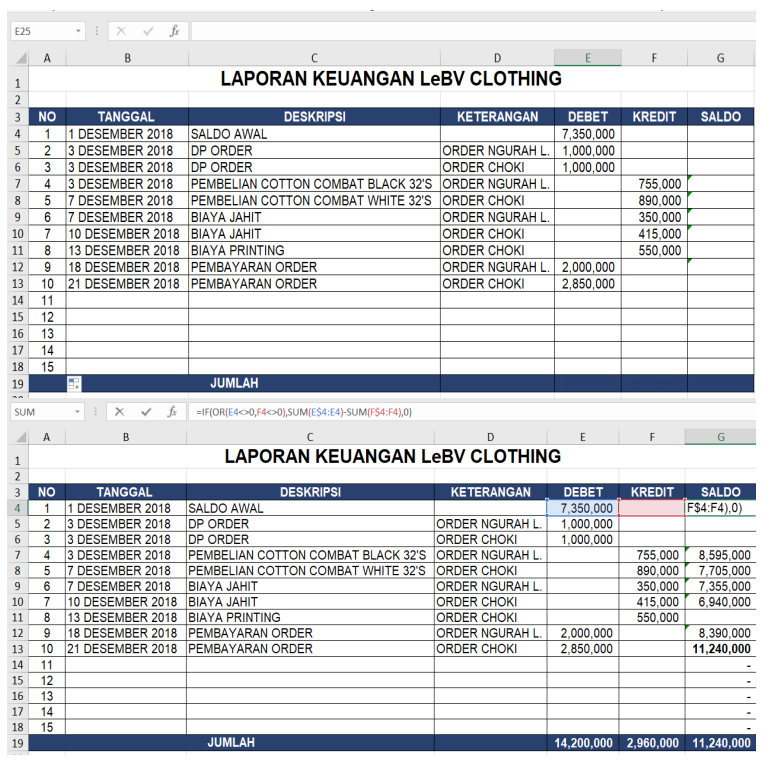

Gambar 3. Memasukkan data dan membuat rumus sederhana untuk laporan keuangan
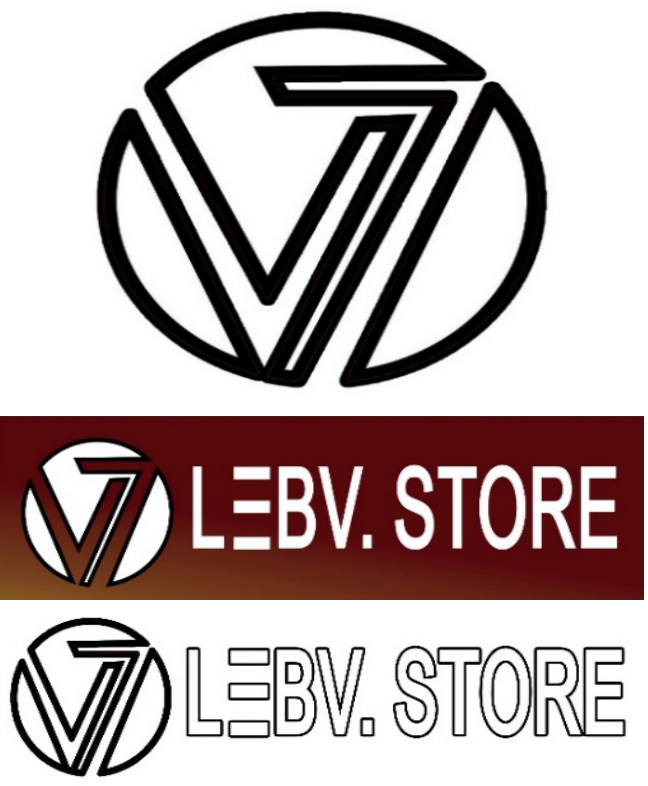

Gambar 4. Logo dan Label woven Mitra

Pada monitoring dan evaluasi kegiatan yang dilakukan melalui questionnaire, mitra menjawab beberapa pertanyaan pada questionnaire terkait pelaksanaan kegiatan pengabdian. Pertanyaan yang diajukan terkait relevansi pelatihan, isi pelatihan, bahan pelatihan, narasumber, kegiatan pelatihan, tujuan pelatihan, agenda pelatihan, kinerja instruktur, fasilitas pelatihan, kesesuaian waktu serta kepuasan peserta mengikuti pelatihan. Secara keseluruhan hasil monitoring dan evaluasi dari mitra, $45.45 \%$ menyatakan baik dan $54.55 \%$ menyatakan sangat baik. Selain itu, mitra menyatakan bahwa waktu pelatihan sudah sesuai dengan waktu mitra. Mitra menyatakan pelatihan yang telah diselenggarakan memberikan manfaat dalam pengelolaan keuangan, mitra menyatakan materi yang diberikan mudah dipahami. Terkait identitas produk konfeksi yaitu desain logo dan label woven mitra sepakat untuk menggunakan identitas tersebut. Selain itu 
berdasarkan pendapat yang diberikan mitra menyatakan puas dengan pelaksanaan pelatihan dan saran yang diberikan adalah agar kedepannya kegiatan pelatihan seperti ini dapat dilaksanakan secara berkelanjutan dan waktu pelaksanaan pelatihan lebih lama. Grafik monitoring dan evaluasi kegaitan dapat dilihat pada Gambar 5.

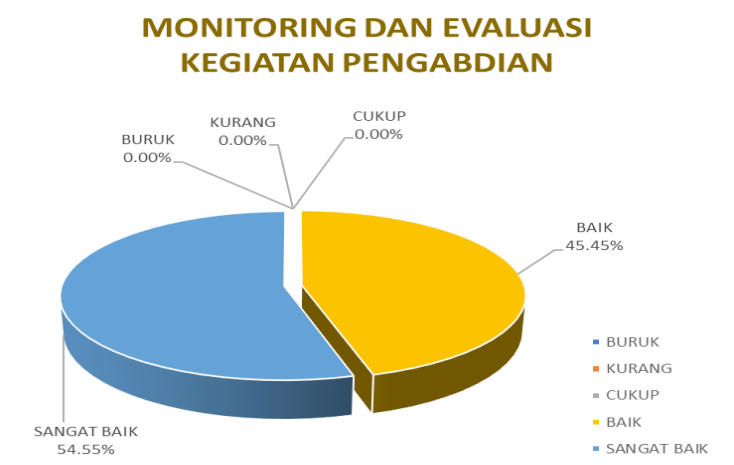

Gambar 5. Grafik Monitoring dan Evaluasi Kegiatan

Pada penilaian kegiatan yang juga dilakukan melalui questionnaire, mitra menjawab beberapa pertanyaan pada questionnaire terkait pelaksanaan kegiatan pengabdian. Pertanyaan yang diajukan terkait pelaksanaan kegiatan dan pembicara. Berdasarkan hasil jawaban mitra, secara keseluruhan hasil penilaian kegiatan dari mitra, $100 \%$ menyatakan kegitan pengabdian masyarakat memuaskan. Grafik penilaian kegiatan dapat dilihat pada Gambar 6

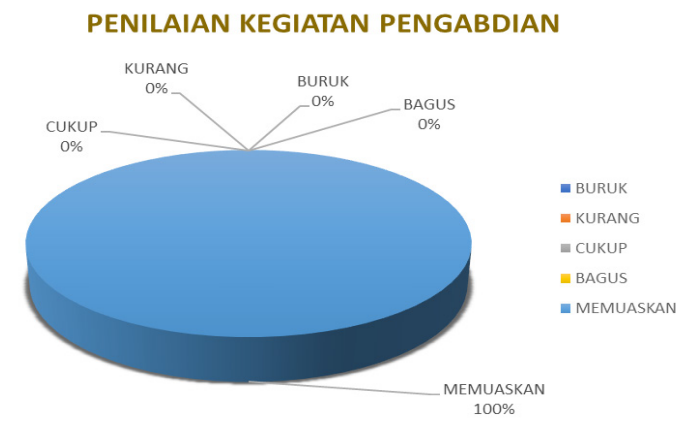

Gambar 6. Grafik Penilaian Kegiatan

\section{SIMPULAN}

Adapun kesimpulan yang dapat diambil dari kegiatan pengabdian ini adalah sebagai berikut :

1. Mitra memperoleh pengetahuan mengenai bagaimana memanfaatkan pengetahuan pengelolaan keuangan yaitu pencatatan pembelian bahan baku, pencatatan pengeluaran, serta pencatatan penjualan produk bambu. menggunakan Ms. Excel.

2. Mitra dapat menghasilkan sebuah dokumen pengelolaan keuangan sehingga memudahkan mitra dalam mengetahui pengeluaran dan penghasilan setiap bulan.

3. Secara keseluruhan hasil monitoring dan evaluasi dari mitra, $45.45 \%$ menyatakan baik dan $54.55 \%$ menyatakan sangat baik.

4. Mitra memiliki identitas produk konfeksi yang dapat digunakan sebagai media pemasaran.

\section{DAFTAR PUSTAKA}

Ernawati, Izwerni, Nelmira W., Tata Busana, Direktorat Pembinaan Sekolah Menengah Kejuruan, 2008

Febriansyah, Nabila, N.I., Pengaruh Logo Baru PT. Telkom, Tbk terhadap Citra Perusahaan, Journal of Innovation in Business and Economics, Vol 5, No. 2 , Juli 2014

Iqbal S., Agus H.P., Modul Microsoft Excel, Kementerian Keuangan RI, Badan Pendidikan dan Pelatihan Keuangan, Pusdiklat Keuangan Umum, 2013

Jerusalem AM, Manajemen Usaha Busana, Universitas Negeri Yogyakarta, 2011

Setia M., Manajemen Keuangan, Penerbit Pustaka Setia, 2015

Supranto J., Statistik Teori dan Aplikasi, Penerbit Erlangga, 2000 